\title{
COVID-19 Pandemic - Impact on Deep Neck Space Infections: a Retrospective Cohort Study
}

\author{
Alexander Charlton ${ }^{1}$, Raul Simon ${ }^{1}$, and Anthony Simons ${ }^{1}$ \\ ${ }^{1}$ Nottingham University Hospitals NHS Trust
}

February 5, 2022

\begin{abstract}
Abstract Background This study aimed to evaluate whether changes in practice and patient behaviour due to the covid-19 pandemic impacted the presentation, management, and outcomes of patients with deep neck space infections (DNSI). Design Retrospective cohort study including all adults presenting to the otolaryngology department at a tertiary UK centre with a DNSI during the first 12 months of the covid-19 pandemic $(\mathrm{n}=27)$, and those from the previous 12 month period $(\mathrm{n}=26)$. Patients with peritonsillar abscess which did not involve deep neck spaces radiologically were excluded. Results The covid-19 pandemic cohort tended to present later after onset of symptoms (5.96 days vs 3.25 days, $\mathrm{p}=0.0277$ ), have abscess formation rather than inflammation only $(77.8 \%$ vs $34.6 \%, \mathrm{p}<0.01)$, and develop complications $(33.3 \%$ vs $7.7 \%, \mathrm{p}=0.0394)$. Not reaching statistical significance, the covid-19 pandemic cohort also had larger volume abscess $(25.18 \mathrm{~cm} 3 \mathrm{vs} 14.5 \mathrm{~cm} 3, \mathrm{p}=0.291)$, longer hospital stay (14.48 days vs 6.35 days, $\mathrm{p}=0.114$ ), and longer intensive care stay ( 7.88 days vs 1.78 days, $\mathrm{p}=0.0992)$. Non-significant changes were noted in management, with the covid-19 pandemic cohort being seven times more likely to undergo tracheostomy $(25.9 \%$ vs $3.8 \%, \mathrm{p}=0.0504)$, and more likely to undergo transcervical drainage $(37 \%$ vs $19.2 \%, \mathrm{p}=0.224)$ and hot tonsillectomy $(11.1 \%$ vs $0 \%, \mathrm{p}=0.236)$. Conclusion This study demonstrates the covid-19 pandemic led to delayed presentation and more severe infection, requiring more radical management in patients with DNSI.
\end{abstract}

\section{Abstract}

Key words: COVID-19, pandemic, deep neck space infection, deep neck space abscess, tracheostomy, severity, lockdown, delayed presentation, tracheostomy, quinsy.

\section{Background}

This study aimed to evaluate whether changes in practice and patient behaviour due to the covid-19 pandemic impacted the presentation, management, and outcomes of patients with deep neck space infections (DNSI).

\section{Design}

Retrospective cohort study including all adults presenting to the otolaryngology department at a tertiary UK centre with a DNSI during the first 12 months of the covid-19 pandemic $(\mathrm{n}=27)$, and those from the previous 12 month period $(\mathrm{n}=26)$. Patients with peritonsillar abscess which did not involve deep neck spaces radiologically were excluded.

\section{Results}

The covid-19 pandemic cohort tended to present later after onset of symptoms (5.96 days vs 3.25 days, $p$ $=0.0277$ ), have abscess formation rather than inflammation only ( $77.8 \%$ vs $34.6 \%, p<0.01$ ), and develop complications $(33.3 \%$ vs $7.7 \%, p=0.0394)$. Not reaching statistical significance, the covid-19 pandemic 
cohort also had larger volume abscess $\left(25.18 \mathrm{~cm}^{3}\right.$ vs $\left.14.5 \mathrm{~cm}^{3}, p=0.291\right)$, longer hospital stay (14.48 days vs 6.35 days, $p=0.114$ ), and longer intensive care stay (7.88 days vs 1.78 days, $p=0.0992)$. Non-significant changes were noted in management, with the covid-19 pandemic cohort being seven times more likely to undergo tracheostomy $(25.9 \%$ vs $3.8 \%, p=0.0504)$, and more likely to undergo transcervical drainage $(37 \%$ vs $19.2 \%, p=0.224)$ and hot tonsillectomy $(11.1 \%$ vs $0 \%, p=0.236)$.

\section{Conclusion}

This study demonstrates the covid-19 pandemic led to delayed presentation and more severe infection, requiring more radical management in patients with DNSI.

\section{Key points}

1. There is a significant demographic shift towards females presenting with DNSIs during the covid-19 pandemic.

2. Patients diagnosed with DNSIs have a significantly delayed presentation during the covid-19 pandmeic.

3. Patients diagnosed with DNSIs are significantly more likely to have abscess formation rather than inflammation/phlegmon alone during the cpovid-19 pandemic.

4. Patients are significantly more likely to develop compliocations of DNSIs during the covid-19 pandemic.

5. Patients diagnosed with DNSIs are seven times more likely to undergo tracheostomy during the covid-19 pandemic.

\section{Introduction}

\section{Background}

A deep neck space infection is a serious condition characterised by rapid progression and severe morbidity with a high mortality rate. In addition, it also carries a high cost burden to the National Health Service (NHS) as management is complex necessitating input from several specialities and often a prolonged hospital stay $(1,2)$. The most common causes are dental and tonsillar infections, but also salivary gland infections, lymphadenitis, foreign bodies and neoplasm (3). The infection is often polymicrobial (4), resulting in inflammation of deep neck space tissues or abscess formation within tissue planes. Antimicrobials, surgical drainage of abscesses and supportive treatment are the mainstay of management (4). The airway is often compromised and requires securing with endotracheal intubation or tracheostomy (5). The incidence and severity of DNSI reduced significantly in the era of readily available antibiotics, partly due to early treatment of predisposing infections. In recent years, however, the incidence of DNSIs appears to be rising $(2,3)$.

In response to the covid-19 pandemic, the United Kingdom went into lockdown on $26^{\text {th }}$ March 2020, with further national lockdowns coming into force on $5^{\text {th }}$ November 2020 and $6^{\text {th }}$ January 2021 in England. Restrictions varied over time and location following the first national lockdown easing, with some form of restriction remaining in place to date (6).

The Covid-19 pandemic has caused people to avoid presentation to hospitals and primary care (7). It has also reduced capacity for face-to-face primary care consultation and examination, especially for upper respiratory tract symptoms such as a sore throat. Changes in the hospital management and allocation of hospital resources, particularly intensive care capacity and availability also ensued (8).

Several studies have evaluated the impact of the covid-19 pandemic on upper respiratory tract, pharyngeal and orofacial/cervicofacial infections, including DNSIs $(9,10,11,12)$. Still, none have assessed the effect of the pandemic on the management of these infections - a particularly pertinent point given the frequent requirement for airway management in the context of concern around intensive care capacity and aerosolgenerating procedures. The published data evaluating the presentation and outcomes of patients with DNSIs is limited and does not exist in a United Kingdom (UK) setting. 


\section{Objectives}

We investigated the impact of the covid-19 pandemic on presentation, outcomes and management of DNSIs. We hypothesised that patients were more likely to present later with more advanced/severe disease for the reasons discussed above. Due to the scarcity of intensive care beds (8), we postulated that patients requiring airway management were more likely to have tracheostomy performed as this negates the mandatory intensive care admission associated with endotracheal intubation.

\section{Methods}

This manuscript was prepared using the STROBE checklist for cohort studies (13). Neither ethical approval nor participant consent were required due to the retrospective nature of this study and anonymous handling and reporting of data.

\section{Study design}

Retrospective cohort study comparing patients with DNSI presenting during the covid-19 pandemic with those presenting beforehand.

\section{Setting}

Patients presenting to the ear, nose and throat (ENT) department of a NHS teaching hospital in the UK during the period $1^{\text {st }}$ April 2019 to $31^{\text {st }}$ March 2020 (pre-covid-19 pandemic cohort) and $1^{\text {st }}$ April 2020 to $31^{\text {st }}$ March 2021 (covid-19 pandemic cohort). Data was collected retrospectively, from April 2021 to August 2021.

\section{Participants}

We enrolled all patients at least 16 years of age (at time of presentation) with a DNSI in the specified timeframes. Cases were identified by interrogating daily ENT in-patient handover lists for the relevant periods. Potential deep neck space infections were then confirmed or refuted using digital health records and PACS systems. All patients had radiological evidence of deep neck space infection, either inflammatory changes/phlegmon or abscess. Patients with peritonsillar abscess which did not involve deep neck spaces radiologically were excluded.

\section{Variables}

Data points and outcome measures included basic patient demographics, duration of symptoms and antibiotic administration prior to presentation, the presence of deep neck space abscess vs inflammation/phlegmon only, complications from DNSI (specifically Lemierre's syndrome and mediastinitis), mortality. The management of DNSI was divided into transoral drainage in theatre, transcervical drainage in theatre, hot tonsillectomy, bedside peritonsillar abscess drainage, or medical management alone, and whether a tracheostomy was performed. Other outcome measures included intensive care admission, duration of intensive care admission, length of hospital stay, and abscess volume.

\section{Data sources/measurement}

All data was identified from digital health records, with the exception of the presence of deep neck space abscess vs inflammation/phlegmon only and abscess volume which were assessed using PACS system reports.

\section{Bias}

A 12 month time period was used for each cohort to mitigate bias from seasonal variation in DNSIs. 


\section{Study size}

The study size was dictated by the timeframe and eligibility criteria which are key to the design of this study.

\section{Quantitative variables/Statistical methods}

Data was analysed using Microsoft Excel. Categorical variables were presented as frequencies and percentages, and p-values calculated using Fisher Exact Test. Continuous variables were presented as mean with standard deviation, with p-values calculated using unpaired t-tests. Statistical significance was attributed to $\mathrm{p}$ values $<0.05$.

\section{Results}

During the pre-covid period, 26 patients presented with deep neck space infections, and 27 patients presented during the covid period. Patient demographics for the two groups are shown in table 1. Results and statistical comparison between groups are summarised in table 2 .

\section{Discussion}

\section{Key results and interpretation}

A male predominance is generally observed for deep neck space infections (14) - this was witnessed in our pre-covid cohort, but there were more females in our covid-19 pandemic cohort $(p=0.0244)$. This may be because women are more likely than men to avoid or delay medical attention as a result of the covid-19 pandemic (7), resulting in untreated predisposing infections progressing to DNSIs.

The incidence of DNSIs was similar between the two groups (pre-covid-19 pandemic cohort $=26$, covid19 pandemic $=27)$. Existing studies evaluated orofacial and respiratoryinfections (9); oropharyngeal and DNSIs (10); and odontogenic cervicofacial infections (11, 12), without specifically focusing on DNSIs as a pathological and clinical entity. They all showed a reduction in incidence during the covid-19 pandemic. Despite this, during the covid-19 pandemic, DNSIs showed greater incidence (15), likely due to progression of simple infections which were not treated promptly.

Our results have proven our hypothesis true, demonstrating patients present significantly later - a mean of 5.96 days after onset of symptoms in the covid-19 pandemic cohort compared to 3.25 days in the pre-covid-19 pandemic cohort $(p=0.0277)$. This concurs with findings for odontogenic cervicofacial (12), oropharyngeal and DNSIs (10).

Toppi et al. identified a reduced number of patients already having antimicrobial treatment at presentation, hypothesised to be due to limited access to primary care clinicians and apprehension about - as well as general advice against - attending medical facilities during the covid-19 pandemic (10). Contrarily, in our study, the likelihood of pre-hospital antibiotic administration was similar in cohorts. Unfortunately, we could not reliably assess when antibiotic therapy was initiated for those who had started antibiotics before presentation. If we were able to access this data, it might have shown that antibiotics were initiated later in the course of the disease in the pandemic cohort for the above reasons

As postulated, the covid-19 pandemic caused people to have more severe/advanced disease, likely resulting from the delayed presentation. We found a significantly $(p<0.01)$ increased likelihood of abscess formation in the covid-19 pandemic cohort (77.8\%) compared to the pre-covid-19 pandemic cohort $(34.6 \%)$ as well as greater volume of the abscess in the covid-19 pandemic cohort ( mean $=25.18 \mathrm{~cm}^{3}$ ) compared to the pre-covid19 pandemic cohort $\left(\right.$ mean $\left.=14.5 \mathrm{~cm}^{3}\right)$. This likely reflects the delayed presentation, allowing the infection longer to mature into an abscess in the covid-19 cohort. Existing literature reports an increased proportion of dental and odontogenic cervicofacial infections were considered to be severe $(11,16)$, or demonstrated systemic inflamatory response syndrome (12), during the covid-19 pandemic. 
Complications were also more likely in the covid-19 pandemic cohort, affecting $33.3 \%$ of participants, compared with $7.7 \%$ of the pre-covid-19 pandemic cohort, again implying more advanced and severe disease $(p$ $=0.0394)$. Perhaps the most significant complication is mediastinitis with mortality rates reported as high as $40 \%(17,18)$. We found a slightly higher rate of mediastinitis in the covid-19 pandemic cohort (4 vs 3 ), which could be linked to delayed presentation and corresponding increased severity. A significant rise in neck infections progressing to mediastinitis has been reported during the covid-19 pandemic (19). Mortality was infrequent in both our study groups $(3.8 \%$ and $7.4 \%)$, with frequencies too rare to make valid comparisons.

Probably due to the increased severity of disease and higher rate of complications, often necessitating airway securement, the covid-19 pandemic cohort had longer hospital stay (mean days 14.48 vs $6.35, p=0.114$ ), in-keeping with findings for odontogenic cervicofacial infections (12). Intensive care stay was also longer in the covid-19 pandemic cohort (mean days 7.88 vs $1.78, p=0.0992$ ).

Tracheostomy was seven times as likely in the covid-19 pandemic cohort $(25.9 \%$ vs $3.8 \%, p=0.0504)$. With a p-value so close to significance, we feel the seven-fold increase in tracheostomies in the covid-19 cohort is a strong indicator of the management pattern during the pandemic. This may represent the increased severity of disease, more often involving complications and necessitating airway management. It may also reflect the scarcity of intensive care beds (8), meaning patients were more likely to undergo tracheostomy rather than orotracheal intubation, as tracheostomy negates the need for intensive care admission. Tracheostomy formation, however, presents its own challenges during the covid-19 pandemic as the procedure, and associated ward-based tracheostomy care is considered aerosol-generating (20).

Aerosol generating procedures and the risk of covid-19 transmission may have a significant impact on the way patients with DNSIs are managed during the covid-19 pandemic. These implications were demonstrated in a case presentation by Ajeigbe et al (21). They highlighted several potential impacts: hesitancy to examine the mouth/oropharynx or perform flexible nasendoscopy; hesitancy to perform surgery or bedside drainage of abscesses; pressure to avoid hospital admission and to discharge patients early to maintain hospital bed occupancy (21). These factors may result in suboptimal treatment of patients with DNSIs causing progression to more severe disease and may contribute to our discovery of the greater risk of complications, longer hospital stay, and potential need for more radical interventions such as tracheostomy.

One would expect that the hesitation to perform invasive procedures during the covid-19 pandemic would increase the number of patients treated with medical therapy alone. However, the rate of management with medical therapy alone was similar in the two groups. We propose this is balanced against a cohort where abscess formation is more common and larger, and infection is more severe with a higher incidence of complications.

There is, however, a noticeable reduction in transoral manoeuvres, including bedside peritonsillar abscess drainage and transoral drainage under general anaesthesia, being performed almost twice as rarely in the covid-19 pandemic cohort. This may indicate the intended decrease in transmission of the virus, but has potentially hindered the progress of these patients.

Twice as many patients had transcervical drainage in the covid-19 pandemic cohort, which is likely to reflect the increased number and size of true abscesses and the increased severity of disease. It may also have been selected as a preferred option over transoral procedures to minimise risks of covid-19 transmission. Dawoud et al also noted an increase in extra-oral drainage for odontogenic cervicofacial infections during the covid-19 pandemic (12).

\section{Study Limitations/Generalisability}

Our study assumes that the covid-19 pandemic is driving the identified differences. However, the authors acknowledge that there may be confounding factors. One such factor is the comorbid status of the patients as this is predictive of complications $(22,23)$ and length of stay $(23,24)$. We did not collect data on comorbidities and therefore are unable to assess their impact in our study. The observed difference in gender make-up of the cohorts could confound results as well. 
Our study evaluated the same time period, a full calendar year, for each cohort, which is a different methodology to others that considered brief periods at the onset of the covid-19 pandemic only $(10,11)$ and would have been subject to bias as a result, especially given the seasonal variations in DNSIs (25).

Our relatively modest number of patients included means many of our results lack statistical power, and larger studies would be required to corroborate our findings. This data also represents only patients at one centre and those under the care of the ENT team, so results may not be generalisable to patients in other geographical locations, other healthcare settings or other specialities such as maxillofacial services. This point is particularly pertinent as responses to the covid-19 pandemic varied by region or country.

Finally, DNSI does not have an agreed definition or a diagnostic code assigned to it, which limits the reliability of our findings.

\section{Conclusion}

This study demonstrates that patients with DNSI were more likely to present later in the course of their disease during the first year of the covid-19 pandemic compared to the year prior. This led to increased likelihood of developing an abscesses rather than inflammation alone, and developing complications from their DNSI. Though not statistically significant, patients were also found to have a longer hospital and ITU stay, during the covid-19 pandemic. Management of DNSI differed during the pandemic, with an increased frequency of tracheostomy and transcervical drainage, and a reduction in transoral drainage procedures. These findings suggest that individuals presenting in the first year of the covid-19 pandemic tended to have more severe disease, requiring more radical management, likely due to presenting later in the course of their illness as well as changes in practice related to the covid-19 pandemic. Further multicentre studies, preferably covering a wider geographical area and examining broader, more detailed cohorts of patients, are required to fully explain and confirm the impact of the covid-19 pandemic on patients with deep neck space infections.

\section{Funding}

There is no funding to declare.

\section{References}

1. Hurley RH, Douglas CM, Montgomery J, Clark LJ. The hidden cost of deep neck space infections. The Annals of The Royal College of Surgeons of England. 2018 Feb;100(2):129-34.

2. Pankhania M, Rees J, Thompson A, Richards S. Tonsillitis, tonsillectomy, and deep neck space infections in England: the case for a new guideline for surgical and non-surgical management. The Annals of The Royal College of Surgeons of England. 2021 Mar;103(3):208-17.

3. Velhonoja J, Lääveri M, Soukka T, Irjala H, Kinnunen I. Deep neck space infections: an upward trend and changing characteristics. European Archives of Oto-Rhino-Laryngology. 2020 Mar;277(3):863-72.

4. Almuqamam M, Gonzalez FJ, Kondamudi NP. Deep Neck Infections. In: StatPearls. StatPearls Publishing, Treasure Island (FL); 2021. PMID: 30020634.

5. Cho SY, Woo JH, Kim YJ, Chun EH, Han JI, Kim DY, Baik HJ, Chung RK. Airway management in patients with deep neck infections: A retrospective analysis. Medicine. 2016 Jul;95(27).

6. Instituteforgovernment.org.uk: Stack Path [Internet]. Timeline of UK government coronavirus lockdowns and restrictions [Cited 2021 December $23^{\text {rd }}$. Available from: https://www.instituteforgovernment.org.uk/charts/uk-government-coronavirus-lockdowns

7. Czeisler MÉ, Marynak K, Clarke KE, Salah Z, Shakya I, Thierry JM, Ali N, McMillan H, Wiley JF, Weaver MD, Czeisler CA. Delay or avoidance of medical care because of COVID-19-related concerns-United States, June 2020. Morbidity and mortality weekly report. 2020 Sep 11;69(36):1250. 
8. Tyrrell CS, Mytton OT, Gentry SV, Thomas-Meyer M, Allen JL, Narula AA, McGrath B, Lupton M, Broadbent J, Ahmed A, Mavrodaris A. Managing intensive care admissions when there are not enough beds during the COVID-19 pandemic: a systematic review. Thorax. 2021 Mar 1;76(3):302-12.

9. Haapanen A, Uittamo J, Furuholm J, Mäkitie A, Snäll J. Effect of COVID-19 pandemic on orofacial and respiratory infections in ear, nose, and throat and oral and maxillofacial surgery emergency departments: a retrospective study of 7900 patients. European Archives of Oto-Rhino-Laryngology. 2021 Oct 1:1-6.

10. Toppi J, Hughes J, Phillips D. Bacterial infections of the oropharynx and deep neck spaces: An investigation of changes in presentation patterns during the COVID-19 pandemic. ANZ journal of surgery. 2021 Aug 24 .

11. Politi I, McParland E, Smith R, Crummey S, Fan K. The impact of COVID-19 on cervicofacial infection of dental aetiology. British Journal of Oral and Maxillofacial Surgery. 2020 Oct 1;58(8):1029-33.

12. Dawoud BE, Kent P, Ho MW. Impacts of lockdown during the SARS-CoV-2 pandemic on patients presenting with cervicofacial infection of odontogenic origin: a comparative study. British Journal of Oral and Maxillofacial Surgery. 2021 Apr 1;59(3):e109-13.

13. Von Elm E, Altman DG, Egger M, Pocock SJ, Gotzsche PC, Vandenbroucke JP. The Strengthening the Reporting of Observational Studies in Epidemiology (STROBE) statement: guidelines for reporting observational studies. Bulletin of the World Health Organization. 2007;85:867-72.

14. Hasegawa J, Hidaka H, Tateda M, Kudo T, Sagai S, Miyazaki M, Katagiri K, Nakanome A, Ishida E, Ozawa D, Kobayashi T. An analysis of clinical risk factors of deep neck infection. Auris Nasus Larynx. 2011 Feb 1;38(1):101-7.

15. Drew S, Lazar A, Amin D, Abramowicz S. Odontogenic Infections are More Frequent and More Severe during COVID-19 Pandemic. Journal of Oral and Maxillofacial Surgery. 2021 Oct 1;79(10):e88-9.

16. Long L, Corsar K. The COVID-19 effect: number of patients presenting to The Mid Yorkshire Hospitals OMFS team with dental infections before and during The COVID-19 outbreak. British Journal of Oral and Maxillofacial Surgery. 2020 Jul 1;58(6):713-4.

17. Mihos, P., Potaris, K., Gakidis, I., Papadakis, D. and Rallis, G., 2004. Management of descending necrotizing mediastinitis. Journal of oral and maxillofacial surgery, 62 (8), pp.966-972.

18. Roccia F, Pecorari GC, Oliaro A, Passet E, Rossi P, Nadalin J, Garzino-Demo P, Berrone S. Ten years of descending necrotizing mediastinitis: management of 23 cases. Journal of oral and maxillofacial surgery. 2007 Sep 1;65(9):1716-24.

19. Parara E, Krasadakis C, Toursounidis I, Tsekoura K, Mourouzis C, Rallis G. Significant rise in neck infections progressing to descending necrotizing mediastinitis during the COVID-19 pandemic quarantine. Journal of Cranio-Maxillofacial Surgery. 2021 Dec 1;49(12):1182-6.

20. Philpott C, Burrows S; Entuk.org: Aerosol-generating procedures in ENT [Internet]. [Last updated 2020, March 23 ${ }^{\text {rd }}$; Cited 2021, December 23rd]. Available from: https://www.entuk.org/aerosol-generatingprocedures-ent

21. Ajeigbe T, Ria B, Wates E, Mattine S. Severe parapharyngeal abscess that developed significant complications: management during the COVID-19 pandemic. BMJ Case Reports CP. 2020 Dec 1;13(12):e236449.

22. Kumar NJ, Rayanan SG, Greeshma G. A study on deep neck space infections. Otolaryngol Online J. 2017;7(3):159.

23. Barber BR, Dziegielewski PT, Biron VL, Ma A, Seikaly H. Factors associated with severe deep neck space infections: targeting multiple fronts. Journal of Otolaryngology-Head \& Neck Surgery. 2014 Dec;43(1):1-7. 
24. O'Brien KJ, Snapp KR, Dugan AJ, Westgate PM, Gupta N. Risk factors affecting length of stay in patients with deep neck space infection. The Laryngoscope. 2020 Sep;130(9):2133-7.

25. Bakir S, Tanriverdi MH, Gun R, Yorgancilar AE, Yildirim M, Tekbaş G, Palanci Y, Meriç K, Topçu İ. Deep neck space infections: a retrospective review of 173 cases. American journal of otolaryngology. 2012 Jan 1;33(1):56-63.

\section{Hosted file}

Table 1 -- demographic characteristics.docx available at https://authorea.com/users/459034/ articles/555431-covid-19-pandemic-impact-on-deep-neck-space-infections-a-retrospectivecohort-study

\section{Hosted file}

Table 2 -- hospital presentation, infection and patient management characteristics .docx available at https://authorea.com/users/459034/articles/555431-covid-19-pandemic-impact-ondeep-neck-space-infections-a-retrospective-cohort-study 